\title{
INCREASING DURABILITY OF CUTTING TOOLS
}

\author{
Janka Majerníková', Emil Spišák
}

1 Department of Mechanical Technologies and Materials, Faculty of Mechanical Engineering, Technical University of Košice, Košice, Slovakia, e-mail: janka.majernikova@tuke.sk, emil.spisak@tuke.sk

Received: 2017.09 .08

Accepted: 2017.11.01

Published: 2017.12.05

\begin{abstract}
The article evaluates durability of punches and cutting tools when cutting of the cut-outs. Durability of punches made of the same material without coating, with the TiCN-MP coating and with the TiN coating is compared. Durability is evaluated by the tolerance of the cut-outs. Border durability, which requires grinding of the tool, is a determined durability, at which the deviation of the tolerance of a cut-out is at the lowest border. By comparing the dependency of change of the holes' dimensions on the number of strokes in the case of all three types of punches, it can be stated that the durability increased by 10-12 times in the case of the tools with coatings.
\end{abstract}

Keywords: coating, cutting tool,durability

\section{INTRODUCTION}

In the current mass production of various goods resulting from the globalization of production, the final costs of the production are highly influenced by the tools used in the production of the steel sheet cut-outs. The tools should not only provide high quality of the cut-out parts (shape and size stability of the components), but also high durability of the active parts of the cutting tools. Low durability of the cutting tools makes manufacturers often interrupt the production process $[1,9,14]$. However, the re-adjustment of the tools after the re-grinding process requires significant amount of time and well-qualified people.

Specific requirements are imposed on the cutting tools mainly during the process of blanking and punching of the holes of tolerated dimensions. Tolerated holes require also quality cutting surface all over the surface of the cut. Because of short lifetime of these tools, their production is often done in two operations. Chip machining proceeds after the cutting. The reason is that the cutting surface, formed by the influence of the tensile stresses in the area of cut, is characteristic and considerably influenced by the cutting gap but also by the properties of the cut material $[1,10,13,17]$.

Fig. 1 presents the influence that the size of the cutting gap has on the shape of the cutting surface during the punching and blanking. Left part of Fig. 1 a) and b) presents the optimal cutting gap in terms of minimal shear force, right part of Fig. 1 a) and b) presents the cutting surface with the small cutting gap $[1,10,17]$.

These imperfections of the quality of the cutting surface can be eradicated with the technology of accurate cutting, which requires doubleacting or triple-acting presses. Manufactures of steel sheet components often lack this sort of technology. That is why cutting tools need to be adjusting so that the required quality of the cutting surface and the accuracy of dimensions could be also achieved while cutting with the standard eccentric single-acting presses.

In the contribution we will focus on the analysis of durability of the active parts of a cutting tool while cutting out of two tolerated holes on a component according to Fig. 2. 
a)

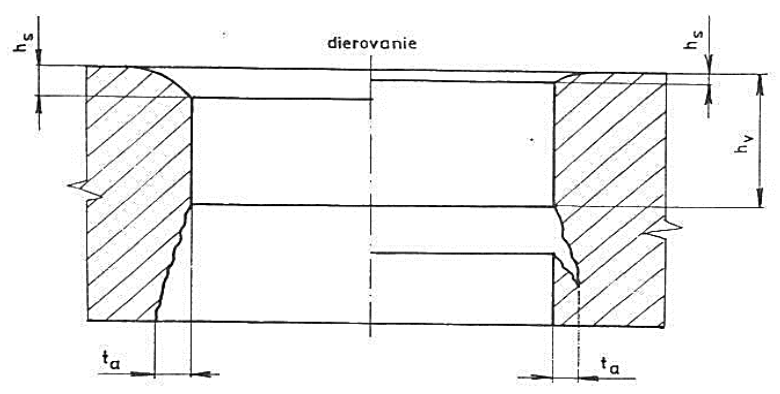

a) punching b)

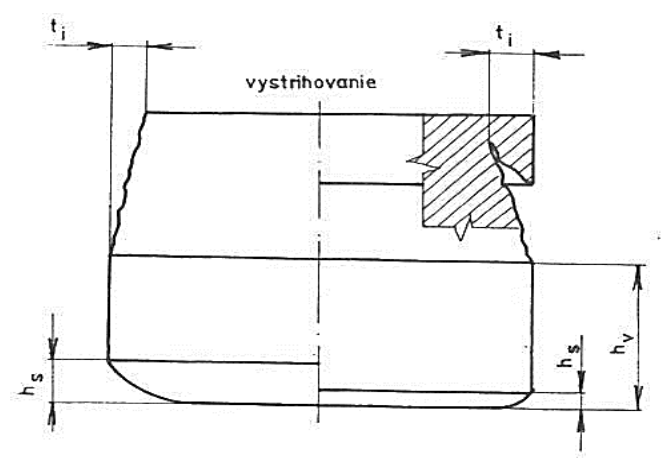

b) blanking

Fig. 1. Shape of the cutting surface
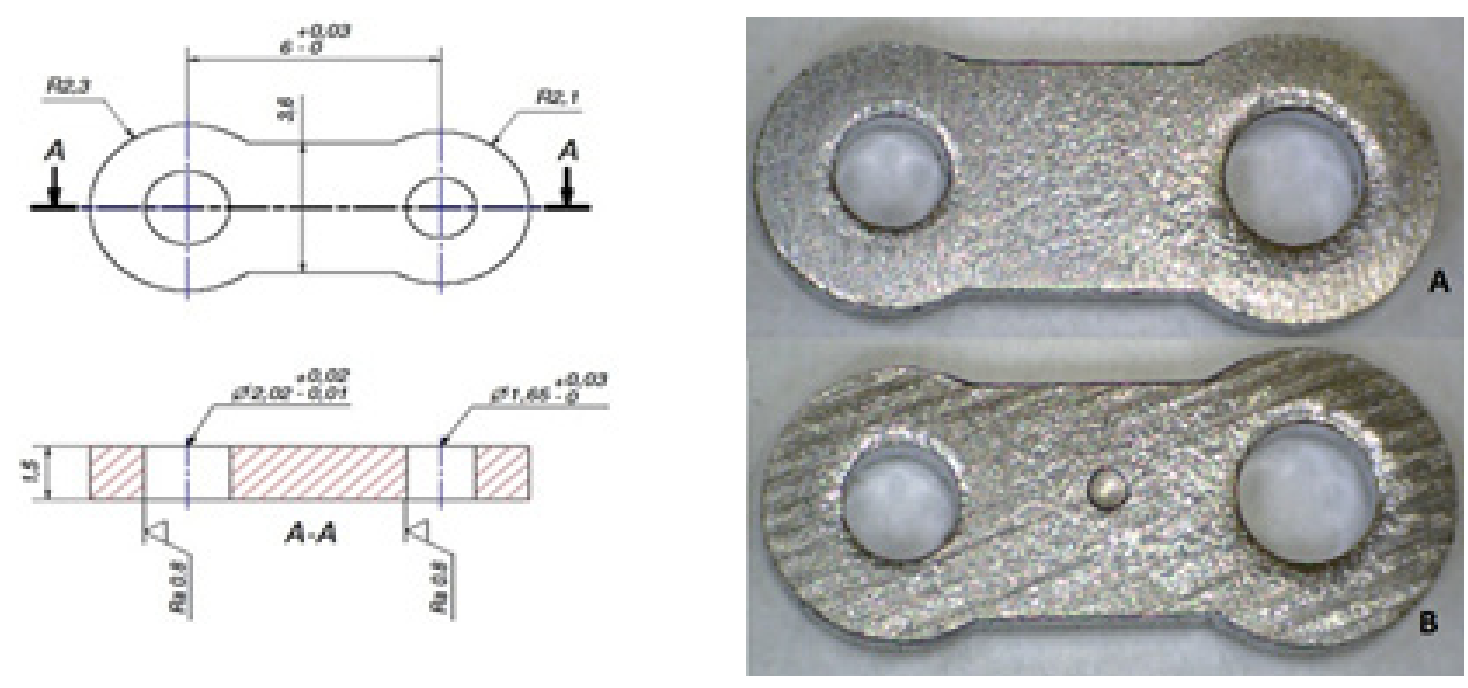

Fig. 2. Shape and dimensions of the cut-out component

\section{EXPERIMENTAL TESTING OF DURABILITY OF THE CUTTING TOOLS}

Durability testing of the cutting tools was done by a company under operating conditions while cutting out of two holes on the component in Fig. 2. This component is nowadays made from the material with the label S235JRG1. Chemical composition of the material is presented in Table 1.

Used material was characterized by inferior cleanness, which is shown in the Fig. 3

In the past, the production of this component went through multiple changes of the cutting tools, which did not result in providing the required durability of the tools. Already after 5000-7000 produced pieces of this component, wear of the punches progressed to the point that punched holes did not satisfy the requirements and tolerance.

Holes on the cut-out component are very small compared to the thickness of the material. To increase the durability, the punches made from carbides (sintered carbides) were tried in the past. During the cutting-out of the holes, these materials did not prove themselves as competent, due to their lower impact strength. This mechanical property caused that these elements were damaged already after several thousand strokes. For the reasons mentioned above, punches for the production of particular holes were made from steel 1.2379 heat treated to the hardness 62-63HRc. Identically produced punches were plated with the coatings TiCN-MP and TiN. Coated parts of the cutting tools are shown in the Fig. 4. 
Table 1. Chemical composition of the material used for the componentin percentage by mass

\begin{tabular}{|c|c|c|c|c|c|c|c|}
\hline $\mathrm{Fe}$ & $\mathrm{C}$ & $\mathrm{Mn}$ & $\mathrm{Si}$ & $\mathrm{P}$ & $\mathrm{S}$ & $\mathrm{Cu}$ & $\mathrm{Al}$ \\
\hline 99.46 & 0.039 & 0.330 & 0.022 & 0.009 & 0.002 & 0.014 & 0.038 \\
\hline $\mathrm{Cr}$ & $\mathrm{Mo}$ & $\mathrm{Ni}$ & $\mathrm{V}$ & $\mathrm{Ti}$ & $\mathrm{Nb}$ & $\mathrm{Co}$ & \\
\hline 0.018 & 0.002 & 0.002 & 0.004 & 0.002 & 0.011 & 0.026 & \\
\hline
\end{tabular}
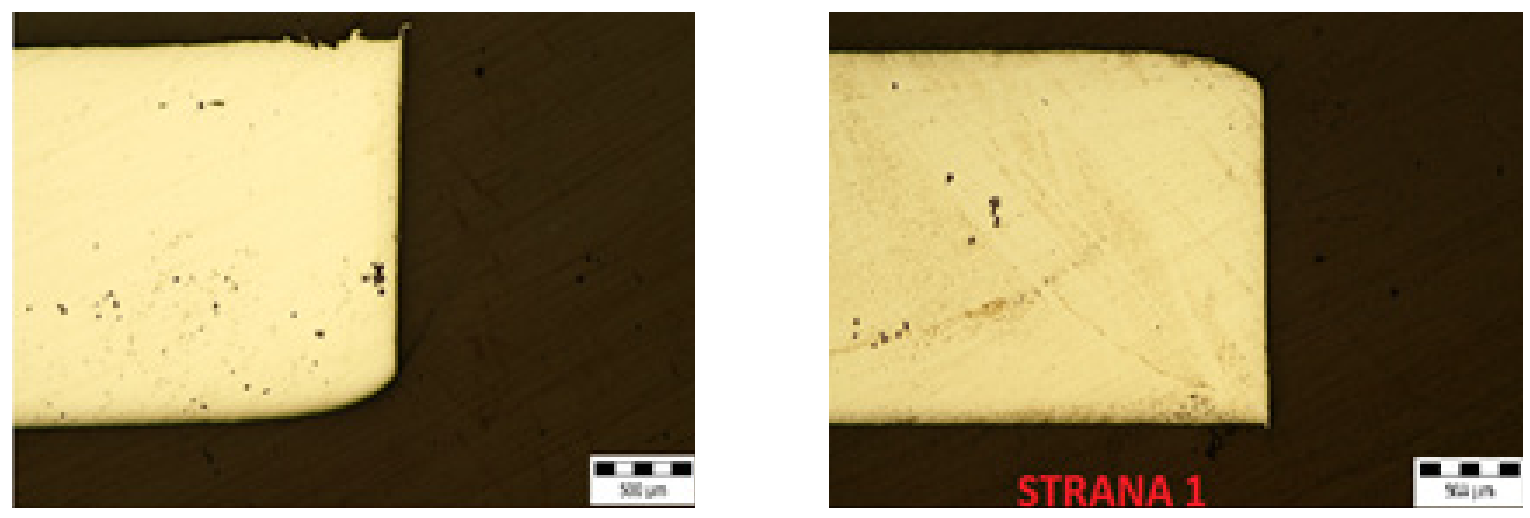

Fig. 3. Cleanness of the material of the cut-out component
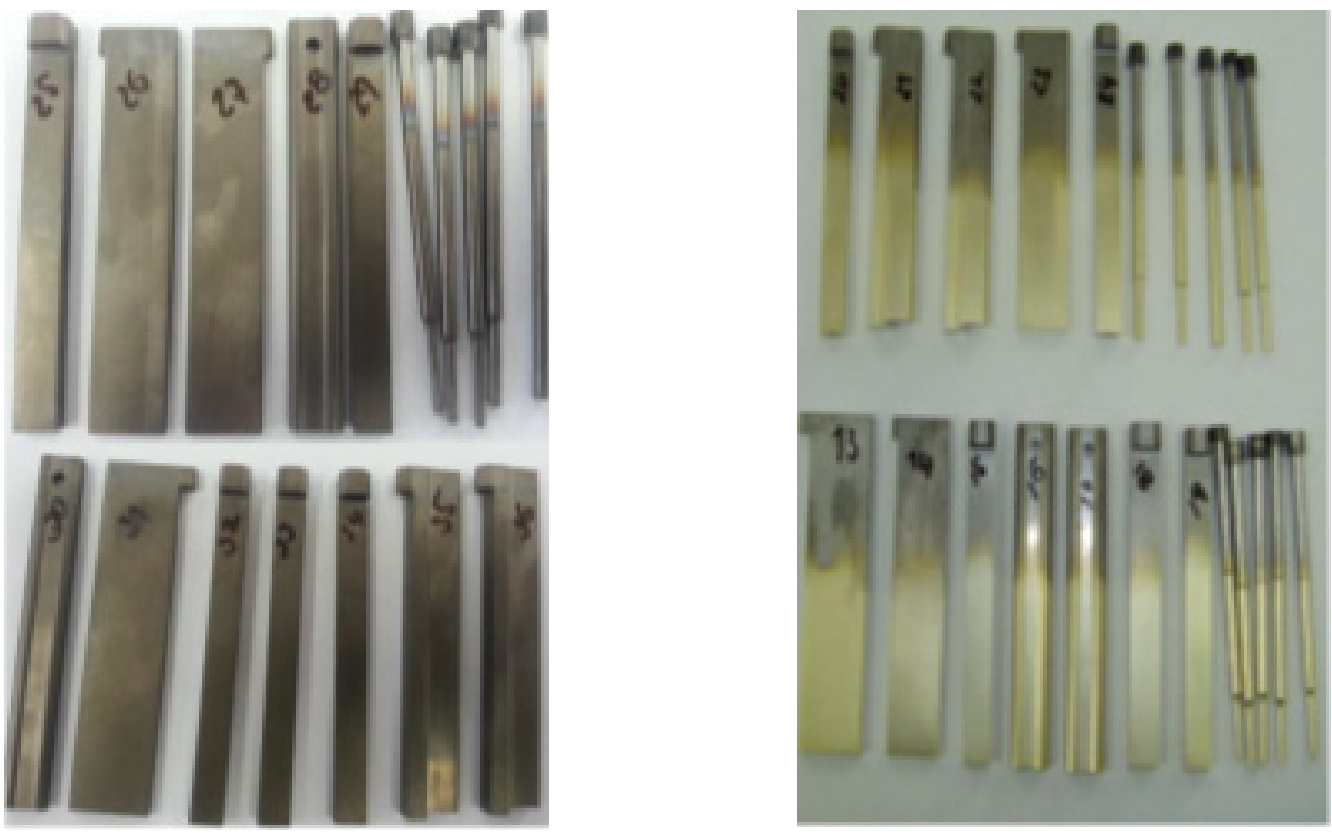

Fig. 4. Coated cutting tools with the coating TiCN (left) and TiN (right)

\section{ACHIEVED RESULTS AND DISCUSSION}

Durability of the active parts of the tool were compared, when the components were cut out by the punch without the coating, punch with the coating TiCN-MP and one with the coating TiN. Limit durability, which requires re-grinding of the tool, is specified by the certain number of strokes, where the tolerance of one of the cut-out holes is at the bottom bound.
A cross-cut of a component in the axis of the holes after 70000 strokes is presented in the Fig. 5. Also through a visual examination we can observe that even after this number of strokes the cut edge of both holes remains perpendicular and the surface remains smooth. Roughness of the inner cut edge of both holes is less than $0.7 \mu \mathrm{m}$.

Dimensions of holes were measured with Keyence microscope. Dimensions of holes on the cut-outs were measured from the side of the 

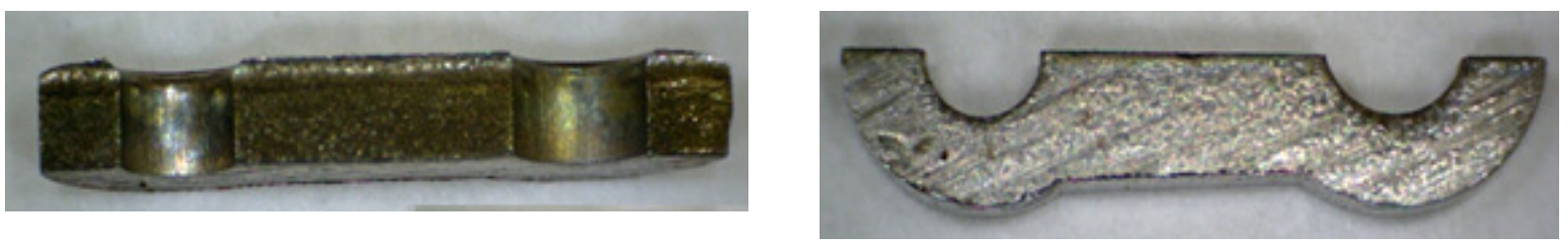

Fig. 5. Cut in the longitudinal axis of the component with the edge (of the holes) after 70000 strokes (cut-outs)

punch and from the side of the die. From both measured sides dimensions had to satisfy the dimensional requirements of the tolerance. In Fig. 6 examples of the measurements done on the holes of the component from the side of the punch are presented and Fig. 7 shows measured dimensions of the holes from the side of the die.

a)

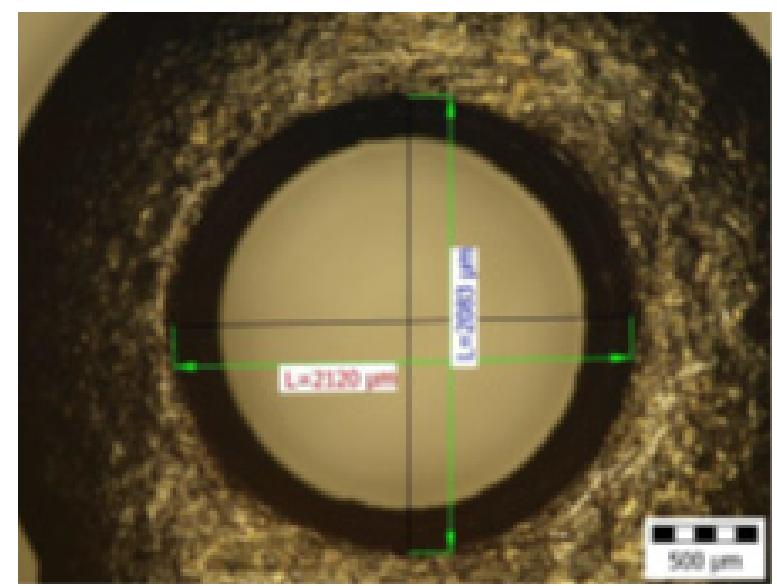

small hole of the component
Dimensions of holes were measured from 1 000 strokes of press up to 70000 strokes. Measurement of the holes until 10000 strokes was more often $(3000,5000,7000)$ because of the ascertaining of durability of uncoated tools. Tools with the coatings TiCN and TiN were used during the cutting without any problems up to 70000

b)

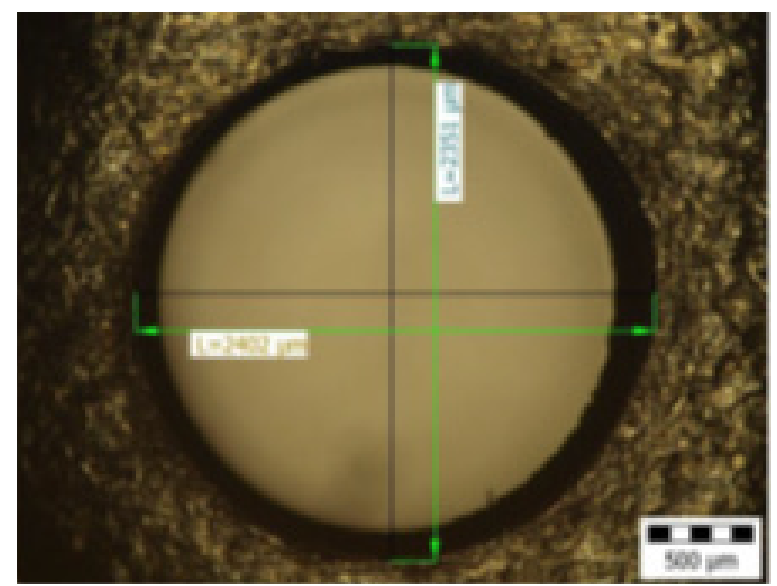

large hole of the component

Fig. 6. Measurement of the holes of the component from the side of the punch

a)

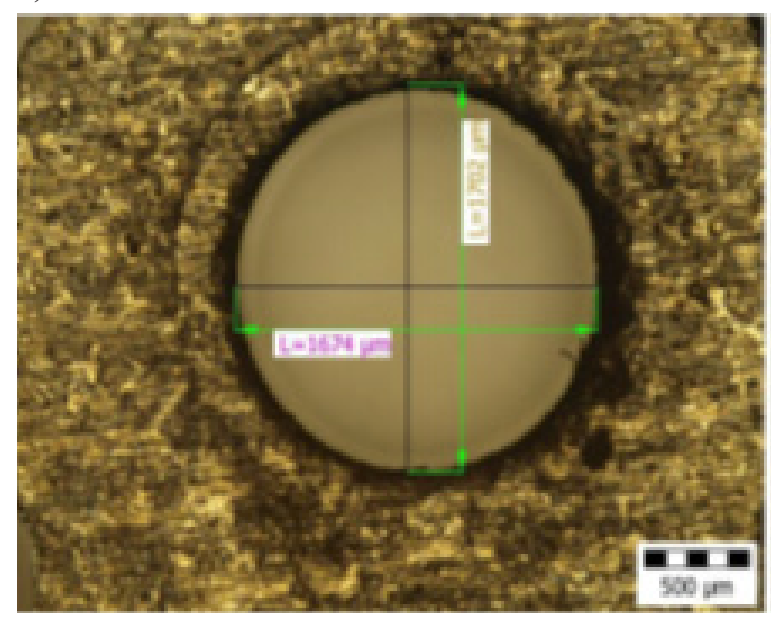

small hole of the component b)

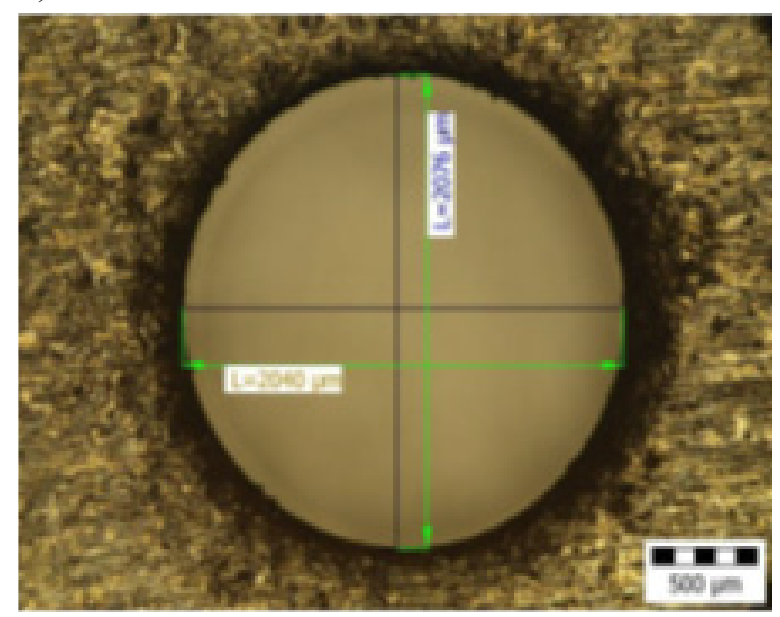

large hole of the component

Fig. 7. Measurement of the holes of the component from the side of the die 
strokes and the components were taken away for measurement after 10000 strokes.

States of the surface of the coating TiCN, at the beginning of the experiment and after 70000 strokes are presented in Fig. 8.

Measured dimensions of the holes with various numbers of strokes $(70000)$ with a tool without a coating and with the coatings TiCN and TiN are presented in Fig. 9.

Fig. 9 a) and b) show us that the punches made of uncoated steel proved to possess low durability, which became obvious as the cut out cylindrical holes were becoming smaller. Both of the cut out holes, large one and small one, were beyond the required tolerance already after 7000 strokes. Both dimensions were smaller. It is an obvious fact because the cut out holes did not have per- pendicular cutting surface, most probably caused by the influence of friction between the material and punch. In the case of coated punches, durability of punches considerably increased and the cut out holes were still within the limit of tolerance even after 70000 strokes.

\section{CONCLUSION}

The article evaluated durability of the punches and the cutting tool while cutting out process of the cut-outs with two tolerated holes. Punches were made of steel 1.2379 heat treated to the hardness $62-63 \mathrm{HRc}$. Identically produced punches were coated with the coatings TiCN-MP a TiN. Dimensions of the holes were measured a)

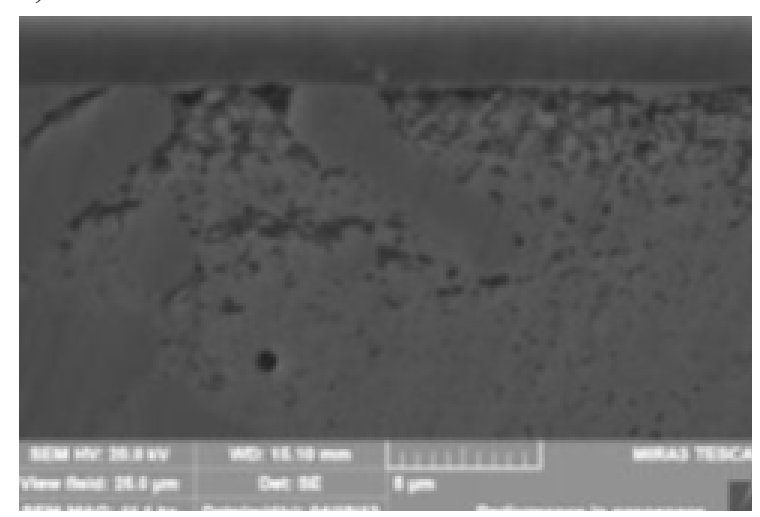

b)

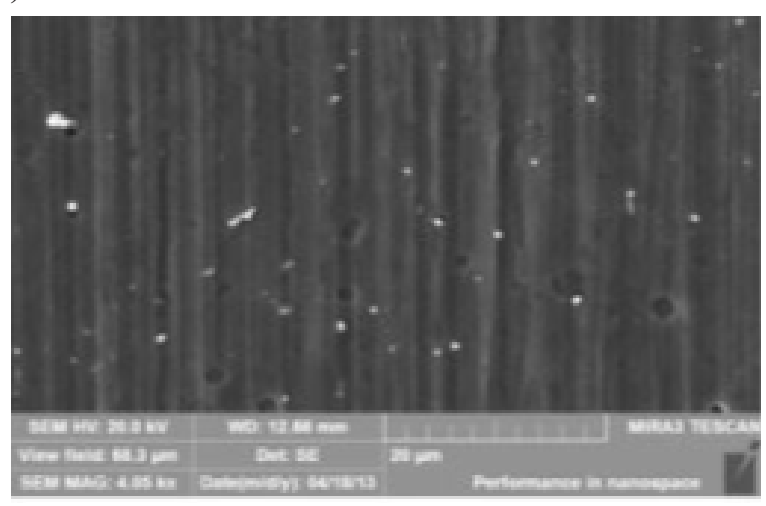

Fig. 8. Cross-cut of the punch with the coating TiCN (a) and the actual surface of the coating after 70000 cut-outs (b)

a)

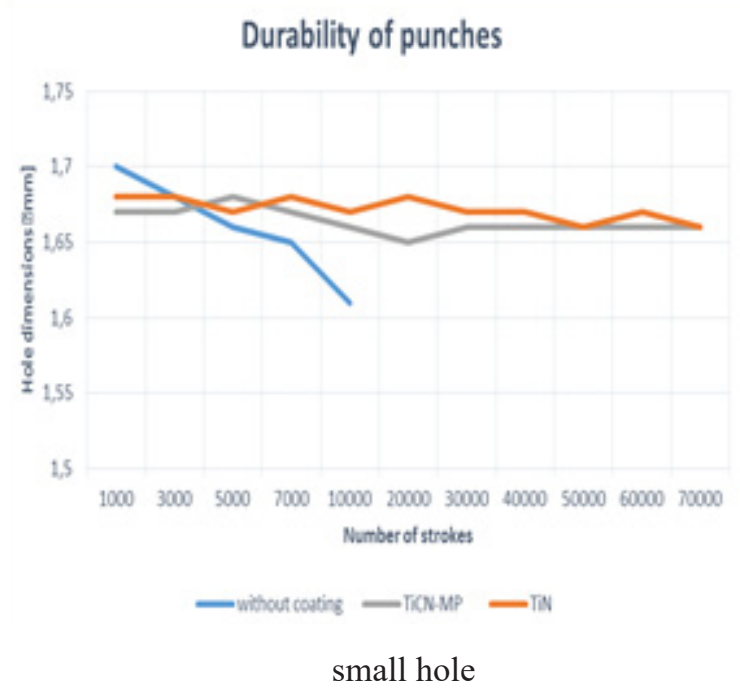

b)

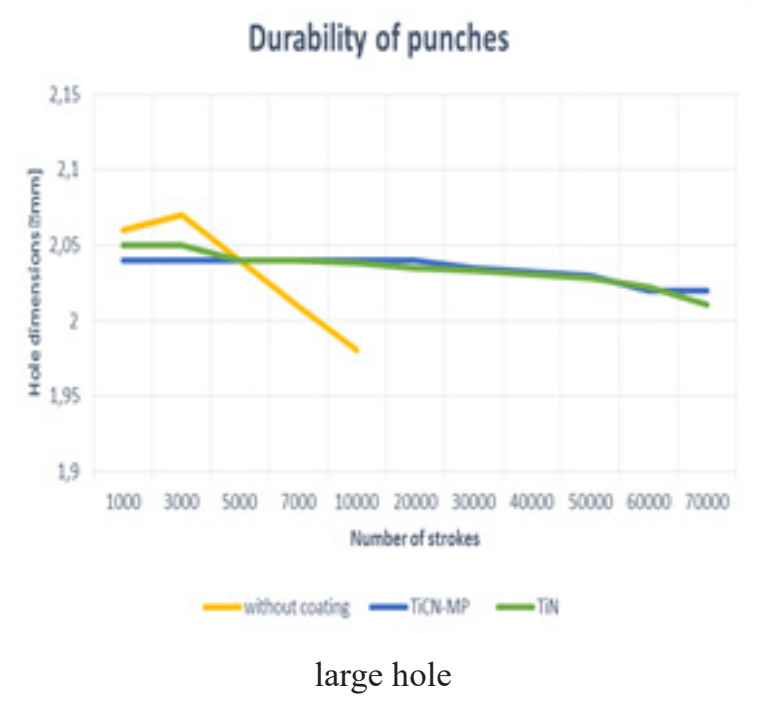

Fig. 9. Dependency of the dimensions of the cut-out holes on the number of strokes 
from the side of punch and from the side of die. Dimensions of the holes were measured with the microscope Keyence. Dependence of dimensions on the amount of strokes in the case of all three types of punches is presented in Fig. 9. The lowest durability of the cutting tool in the case of both types of holes was reached during the cutting process with the uncoated cutting tool. While during the cutting process with the coated cutting tool durability increased by $10-12$ times.

\section{Acknowledgments}

The authors are grateful to APVV for support of experimental work under grant APVV-14-0834

\section{REFERENCES}

1. Frącz W., Kut S. and Stachowicz F., Experimental and numerical investigation of steel sheet blanking with pre-bending, Kovarenstvi, 33, 2008, 121-123.

2. Ibrahim R.N., Rahmat M.A., Oskouei R.H. and Singh Raman R.K. Monolayer TiAlN and multilayer TiAlN/CrN PVD coatings as surface modifiers to mitigate fretting fatigue of AISI P20 steel. Engineering Fracture Mechanics, 137, 2015, 64-78.

3. Józwik J. and Pietras J. Investigation and assessment of occupational risk on the metal cutting machine tool stana. Sci. Technol. Res. J., 7(20), 2013, 47-54.

4. Kim G.S., Lee S.Y., Hahn J.H., LeeB Y., Han J.G., Lee J.H. and Lee, S.Y. Effects of the thickness of Ti buffer layer on the mechanical properties of TiN coatings. Surface and Coatings Technology, 171(1-3), 2003, 83-90.

5. Kottfer D., Ferdinandy M., Kaczmarek L., Trebuńa P. and Hvizdoš, P. The study of selected properties of Ti EB PVD coating deposited onto inner tube surface at lowtemperature. Archives of Metallurgy and Materials, 61(1), 2016, 67-73.

6. Kottfer D., Ferdinandy M., Kaczmarek L., Maňková I. and Beňo J. Investigation of Ti and Cr based PVD coatings deposited onto HSS Co 5 twist drills. Applied Surface Science, 282, 2013, 770-776.

7. Kubík R., Kaščák L. and Spišák E. Wear of PVD coated tools for joining by clinching method. Koroze a Ochrana Materialu, 60(5), 2016, 154-161.

8. Majerníková J. and Spišák E. Punch-Die Gap Effect on Blanked Edge in Fine Blanking of Low-Carbon, Micro-Alloyed and High-Strength Steels. Applied Mechanics and Materials, 474, 2014, 279-284.

9. Majerníková J. and Spišák E. Punch-die gap effect on blanked edge in fine blanking of low-carbon, micro-alloyed and high-strength steels. Applied Mechanics and Materials, 474, 2014, 279-284.

10. Mucha J. Wykrwalność blach prądnicowych, Rozprawa doktorska, Rzeszów, Politechnika Rzeszowska, Wydzial budowy maszyni lotnictwa, 2004

11. Skordaris G., Bouzakis K.D. and Charalampous P.A dynamic FEM simulation of the nano-impact test on mono- or multi-layered PVD coatings considering their graded strength properties determined by experimental-analytical procedures. Surface and Coatings Technology, 265, 2015, 53-61.

12. Spišák E. and Stachowicz F. Deformation analysis of large-sized autobody panels. Journal of Materials Processing Tech., 53(3-4), 1995, 817-826.

13. Spišák E., Majerníková J. and Spišáková E. The Influence of Punch-Die Clearance on Blanked Edge Quality in Fine Blanking of Automotive Sheets. Materials Science Forum, 818, 2015, 264-267.

14. Spišák E., Majerníková J., Kaščák L'. and Slota J. Influence of cutting on the properties of clippings from electrical sheets. Acta Metallurgica Slovaca, 21(4), 2015, 302-310.

15. Spišák E. and Majerníková J. Analysis of variance of mechanical properties of sheets as the input parameters for simulation of processes. Acta Metallurgica Slovaca, 18(2-3), 2012, 109-116.

16. Spišák E., Majerníková J. and Kaščák L. Formability of thin sheets from aluminium alloys Adv. Sci. Technol. Res. J., 10(32), 2016, 248-253.

17. Spišák E., Majerníková J. and Spišáková E. The influence of punch-die clearance on blanked edge quality in fine blanking of automotive sheets. Materials Science Forum, 818, 2015, 264-267.

18. Spišák E. and Majerníková J. Analysis of variance of mechanical properties of sheets as the input parameters for simulation of processes. Acta Metallurgica Slovaca, 18(2-3), 2012, 109-116.

19. Sprute T., Tillmann W., Grisales D., Selvadurai U. and Fischer G. Influence of substrate pre-treatments on residual stresses and tribo-mechanical properties of TiAlN-based PVD coatings. Surface and Coatings Technology, 260, 2014, 369-379.

20. Tanno Y. and Azushima A. Effect of counter materials on coefficients of friction of $\mathrm{TiN}$ coatings with preferred grain orientations. Wear, 266(11-12), 2009, 1178-1184. 